\title{
Central Monoamine Metabolism in the Male Brown-Norway Rat in Relation to Aging and Testosterone
}

\author{
E. GOUDSMIT, ${ }^{1}$ M. G. P. FEENSTRA AND D. F. SWAAB \\ Netherlands Institute for Brain Research, Meibergdreef 33, 1105 AZ Amsterdam (ZO), The Netherlands
}

Received 3 April 1990

\begin{abstract}
GOUDSMIT, E., M. G. P. FEENSTRA AND D. F. SWAAB. Central monoamine metabolism in the male Brown-Norway rat in relation to aging and testosterone. BRAIN RES BULL 25(5) 755-763, 1990. - Concentrations of dopamine (DA), 3,4-dihydroxyphenylacetic acid (DOPAC), homovanillic acid (HVA), noradrenaline (NA), free 3-methoxy-4-hydroxyphenylethyleneglycol (MHPG), serotonin (5-HT) and 5-hydroxyindoleacetic acid (5-HIAA) were determined in brain regions of 5-, 20-, and 32-month-old male Brown-Norway rats using high pressure liquid chromatography. In view of the activating effects of sex steroids on peptide and monoamine transmitter systems and the declining plasma testosterone levels with aging, the effects of testosterone supplementation on age-related changes in central monoamine metabolism were also studied. Age-related decreases in monoamine metabolism were observed in nigrostriatal, mesocortical and coeruleohippocampal systems. Marked reductions in DOPAC (35\%) and HVA (50\%) occurred in the ventral tegmental area between 20 and 32 months of age. 5-HT and 5-HIAA levels showed reductions and increases depending on the brain region. Testosterone administration resulted in elevations of HVA in the substantia nigra and MHPG in the locus coeruleus and hippocampus, which were most pronounced in young animals. It is concluded that there are marked differences in age-related changes between nigrostriatal, mesocortical and coeruleohippocampal systems and that testosterone exerts a stimulatory influence on some aspects of monoamine metabolism in young but not in aged animals.
\end{abstract}

Aging Monoamine metabolism Dopamine Noradrenaline Serotonin Substantia nigra Striatum Ventral tegmental area Frontal cortex Locus coeruleus Hippocampus Testosterone Vasopressin

DURING the aging process many alterations take place in central monoamine systems. In human senescence degenerative changes have been demonstrated in the substantia nigra $(27,29,31)$, which contains dopaminergic cell bodies projecting to the striatum (4), in the locus coeruleus $(31,32,52)$, the main source of noradrenergic projections in the brain (35), and in the dorsal raphe nucleus (32), the origin of the majority of cortical serotonergic projections (13). Concentrations of several monoamine transmitters and metabolites have also been found to decline in various brain areas during human aging (8). More extensive degenerative changes have been reported in the substantia nigra (31), locus coeruleus $(5,31,32)$ and also in the dorsal raphe nucleus $(22,32)$ in Alzheimer's disease. Alterations in concentrations of monoamine transmitters and metabolites have also been shown to be more severe in this condition $(8,22)$.

Data on aging rodents are less straightforward, even if only studies on senescent animals (i.e., at 50\% survival) are considered. An extensive neuronal loss was observed in the substantia nigra of aged rats (46), but Goldman and Coleman (16) found no cell loss in the locus coeruleus of the Fisher 344 rat with aging. In contrast, Sturrock and Rao (51) reported a marked cell loss in this nucleus in senescent ASH/TO mice, suggesting the presence of a species difference. Data on concentrations of monoamine transmitters and metabolites in aged rodents show an even wider variance. Both unchanged $(15,28,45,53)$ and decreased $(30$, $33,42,48$ ) dopamine levels have been reported in the striatum of senescent rats, while increased as well as reduced levels of the metabolites 3,4-dihydroxyphenylacetic acid (DOPAC) and homovanillic acid (HVA) have been reported in this area in senescent rodents [e.g., (30) and (42)]. Comparable discrepancies, which might in part be related to strain differences, were found in other brain regions (3). The present study offers for the first time a detailed description of monoaminergic changes in nigrostriatal, mesocortical and coeruleohippocampal projections in the male BrownNorway rat during the aging process.

In addition to changes in monoamine levels with aging, alterations in several neuropeptide systems which are closely related to monoaminergic systems have been reported in the senescent human and rodent brain [e.g., Joynt and McNeill (23)]. In the male Brown-Norway rat a marked decrease was observed with aging in the sex-steroid-dependent central vasopressin innervation in brain structures including the substantia nigra and the locus coeruleus (14). This decrease corresponds to the age-related decline in testosterone levels and was recently shown to be restored

\footnotetext{
${ }^{1}$ Requests for reprints should be addressed to E. Goudsmit, Netherlands Institute for Brain Research, IWO Building, Meibergdreef 33, 1105 AZ Amsterdam (ZO), The Netherlands.
} 
following peripheral testosterone supplementation to aged animals (17). Since an excitatory effect of vasopressin has been demonstrated on monoaminergic neurons in the rat locus coeruleus, which shows a decline in firing rate with aging $(39,40)$, the question arose, whether restoration of vasopressin innervation in the substantia nigra, the ventral tegmental area and the locus coeruleus following testosterone supplementation would result in a reversal of age-related changes in central monoamine metabolism. Therefore, the effect of testosterone supplementation on age-related changes in central monoamine metabolism was also investigated. This treatment raised central vasopressin levels in the animals used in the present study as reported elsewhere (18).

\section{METHOD}

\section{Animals}

Sixteen young, 16 middle-aged, and 19 aged male BrownNorway (BN/BiRij) rats were housed under standard conditions $\left(21^{\circ} \mathrm{C}\right.$; lights on from 7.00 a.m. to 7.00 p.m.; food and water ad lib). At the time of sacrifice (see below) the animals were 5, 20 and 32 months of age, respectively. The $50 \%$ survival age of this strain is about 30 months (37).

\section{Treatment}

Half of the animals in each age-group were randomly given a subcutaneous implant of $2.5 \mathrm{~cm}$ silastic tubing (SR3, Talas BV, Ommen, The Netherlands; $1.5 \mathrm{~mm}$ i.d.; $2.1 \mathrm{~mm}$ o.d.) under light ether anesthesia. Implants were filled with testosterone (Steraloids Inc., Wilton, NH) and sealed at both ends with silicone. All other rats received empty tubing. Decapitation blood of young, middle-aged and aged animals was collected 7 weeks later [during this period the animals were tested in a Morris water maze, cf. (19)] between 9:00 a.m. and 12:30 p.m. and plasma testosterone levels were determined by radioimmunoassay (43). All animals were inspected for gross pathology. Testes were removed and weighed.

\section{Tissue Treatment}

Brains were quickly removed following decapitation and cut in 1.8-mm thick frontal slices using a preshaped mould. The following areas were dissected unilaterally from the right hemisphere as described by Heffner et al. (20), frozen on dry ice and stored at $-80^{\circ} \mathrm{C}$ until assayed: frontal cortex, striatum (caudate putamen), hippocampus, substantia nigra, ventral tegmental area and locus coeruleus.

\section{Monoamine Determinations}

Concentrations of dopamine (DA), 3,4-dihydroxyphenylacetic acid (DOPAC), homovanillic acid (HVA), noradrenaline (NA), free 3-methoxy-4-hydroxyphenylethyleneglycol (MHPG), serotonin (5-hydroxytryptamine, 5-HT) and 5-hydroxyindoleacetic acid (5-HIAA) were determined as follows:

Frozen tissue samples of substantia nigra, striatum and ventral tegmental area were rapidly weighed and homogenized in $500 \mu \mathrm{l}$ $0.1 \mathrm{M}$ perchloric acid (PCA) to which $1 \mu \mathrm{g}$ ascorbic acid (AA) was added. Frontal cortex, locus coeruleus and hippocampus were homogenized in $1000 \mu \mathrm{PCA}$ /AA. After 20 min centrifugation at $3000 \times \mathrm{g}$ supernatants were injected either directly (frontal cortex, striatum, substantia nigra, ventral tegmental area) or following separation in three fractions on small Sephadex G10 columns (hippocampus and locus coeruleus) in a HPLC system (see below). The purification on Sephadex is indispensable for correct determination of free MHPG and was adapted from Westerink
(54): prewashing with $2 \mathrm{ml} 0.02 \mathrm{M}$ ammonia and $3 \mathrm{ml} 0.01$ $\mathrm{M}$ formic acid; transfer of supernatants to columns; collection of three fractions following washing with $2 \times 1 \mathrm{ml} 0.01 \mathrm{M}$ formic acid (MHPG fraction, $2 \mathrm{nd} \mathrm{ml}$ ), $1.5 \mathrm{ml} 0.01 \mathrm{M}$ formic acid followed by $0.5 \mathrm{ml} 5 \mathrm{mM}$ disodium hydrogen phosphate (NA and DA fraction) and $2 \times 1 \mathrm{ml} 0.1 \mathrm{M}$ potassium hydroxide (DOPAC, HVA, 5-HT and 5-HIAA fraction, collected in tubes containing 1 drop of concentrated formic acid; $25 \mu l 0.4$ mM AA added immediately following collection). Recovery of each component was determined by subtraction of amounts measured in cerebellum with and without known amounts of each component added. Two HPLC systems were used: one consisting of a Waters Wisp, a Waters solvent delivery system and the amperometric Waters 460 detector, and the other of a Hewlett Packard 1090 liquid chromatograph with a Metrohm VA 641 amperometric detector. Both systems contain a $25-\mathrm{cm}$ Supelcosil $5 \mathrm{C} 18-\mathrm{DB}$ column (with guard column) and were operated at $800 \mathrm{mV}$ and $40^{\circ} \mathrm{C}$. The mobile phases used in the various determinations were: 1) $20 \mathrm{mM}$ citric acid/60 mM sodium acetate buffer ( $\mathrm{pH} 4.6)$ with $0.3 \mathrm{mM}$ EDTA, $1 \mathrm{mM}$ heptanesulphonic acid (HSA) and $8 \%(\mathrm{v} / \mathrm{v})$ methanol (direct injection); 2) $40 \mathrm{mM}$ citric acid/60 mM sodium acetate buffer (pH 4.2) with $0.3 \mathrm{mM}$ EDTA and $8 \%(\mathrm{v} / \mathrm{v})$ methanol (MHPG fraction); 3) as in 2) with $1.1 \mathrm{mM}$ HSA (NA/DA fraction); 4) as in 2) with $1.1 \mathrm{mM}$ HSA and $15 \%(\mathrm{v} / \mathrm{v})$ methanol (DOPAC/HVA/ 5-HT/5-HIAA fraction). The flow rate was set to either 0.8 or 1.0 $\mathrm{ml} / \mathrm{min}$. Peak heights were determined using the Waters Baseline 810 HPLC processing program. Concentrations were corrected for recovery.

\section{Statistics}

Means and S.E.M. were calculated for testosterone levels and monoamine and metabolite concentrations in each experimental group. Outliers were detected using Dixon's test and were excluded if they corresponded to dubious tissue dissection or gross chromatographic disturbances as recorded independently. The effects of age and testosterone treatment on plasma testosterone levels, testicular weight and concentrations of monoamines and metabolites in each of the brain structures studied were investigated with analysis of variance (ANOVA). Multiple comparisons were performed using one-way analysis of variance (ONEWAY) and the Student-Newman-Keuls test (SNK). Homogeneity of variance, which is a major requirement for ANOVA, was tested using the Bartlett-Box F-test. If the hypothesis of homogeneity was rejected, ANOVA was applied to rank-transformed data rather than the original data [cf. Conover (12)]. A 0.05 level of significance was used in all statistical tests. If an age $\times$ treatment interaction approached statistical significance $(p<0.10)$ separate comparisons were performed for the individual age and treatment groups.

\section{RESULTS}

\section{Morbidity and Mortality}

Gross pathological examination revealed tumor growth in the liver (2 animals), the lung [2] and the pituitary [2]; a grossly enlarged heart [1]; renal cysts [2] and hydronephrosis [2]. These findings were evenly distributed over aged sham- and testosterone-treated animals. The observed morbidity was in line with data in the literature for the Brown-Norway rat at 30-33 months of age (6).

\section{Testosterone Levels and Testicular Weight}

Testosterone levels fell progressively with age (ANOVA: $p<0.01$ ) and were elevated by testosterone treatment (ANOVA: 
TABLE 1

PLASMA TESTOSTERONE LEVELS (pg/ml) AND TESTICULAR WEIGHT ( $\mathrm{g}$ ) IN SHAMAND TESTOSTERONE-TREATED YOUNG, MIDDLE-AGED AND AGED RATS

\begin{tabular}{|c|c|c|c|c|}
\hline \multirow{2}{*}{$\begin{array}{l}\text { Age } \\
\text { (months) }\end{array}$} & \multicolumn{2}{|c|}{ Plasma Testosterone Level } & \multicolumn{2}{|c|}{ Testicular Weight } \\
\hline & Sham & Testosterone & Sham & Testosterone \\
\hline 5 & $1086 \pm 201$ & $3431 \pm 212$ & $3.44 \pm 0.06$ & $1.73 \pm 0.11$ \\
\hline 20 & $914 \pm 113$ & $2480 \pm 197$ & $2.25 \pm 0.38$ & $1.49 \pm 0.09$ \\
\hline 32 & $764 \pm 64$ & $2435 \pm 91$ & $1.46 \pm 0.11$ & $1.23 \pm 0.12$ \\
\hline
\end{tabular}

Data are means \pm S.E.M. Extremely high testosterone levels which were detected as outliers (Dixon's test: $p<0.05)$ were found in 2 young sham-treated $(11,536$ and 3980 $\mathrm{pg} / \mathrm{ml}), 1$ young testosterone-treated $(6633 \mathrm{pg} / \mathrm{ml}), 1$ middle-aged sham-treated $(3403$ $\mathrm{pg} / \mathrm{ml})$ and 1 aged testosterone-treated rat $(7499 \mathrm{pg} / \mathrm{ml})$ and are not included. Exclusion of these values did not alter the statistical significances; $n=8$ in all other cases. Plasma testosterone levels and testicular weight declined progressively with age (ANOVA: $p<0.01$ ). Testosterone levels were elevated following treatment (ANOVA: $p<0.001$ ), whereas testicular weight was reduced following testosterone administration (ANOVA: $p<0.003$ ).

$p<0.001$; Table 1$)$. No age $\times$ treatment interaction was observed (ANOVA: $p=0.507$ ). Extremely high testosterone levels were found in 5 animals and were detected as outliers. Exclusion of these values did not alter the statistical significances (for details see legend Table 1). Testicular weight also declined with age (ANOVA: $p<0.001$ ). Testosterone treatment resulted in a reduction in testicular weight (ANOVA: $p<0.003$; Table 1). There was no age $\times$ treatment interaction in this respect (ANOVA: $p=$ $0.442)$.

\section{Monoamine Levels}

DOPAC and HVA levels were below the limits of detection in a number of samples (substantia nigra: DOPAC $6 \times$, HVA $10 \times$; ventral tegmental area: HVA $2 \times$ ). Zero values were inserted in these cases and nonparametric statistics using rank-transformed data were used (see above). Outliers were detected in a limited number of determinations and were excluded as described above. The number of values in each experimental group was never under 6.

Nigrostriatal system. Although age did not affect DA levels in the substantia nigra, HVA decreased with aging in this area (Fig. 1). Reductions in the DOPAC/DA ratio with aging in the substantia nigra failed to reach statistical significance, but the HVA/DA ratio was reduced in this area in both middle-aged and aged animals (Fig. 1).

In the striatum aging was accompanied by a gradual decrease in levels of DA, DOPAC and HVA (Fig. 1). The DOPAC/DA and HVA/DA ratios were unaltered in senescence in this area (Fig. 1).

Because the age $\times$ treatment interaction for HVA levels in the substantia nigra approached statistical significance (ANOVA: $p<0.082$ ), the effects of testosterone administration on this metabolite were investigated in each age-group separately. An increase in HVA following testosterone treatment was observed in young animals (ONEWAY: $p<0.05$ ). A similar tendency was observed in middle-aged (ONEWAY: $p=0.060$ ), but not in aged animals (ONEWAY: $p=0.438$; Fig. 1). No significant effects of testosterone treatment were observed on DOPAC/DA and HVA/ DA ratios in this area.

Mesocortical system. Age did not affect DA levels in the ventral tegmental area, but marked reductions ranging from 30 to $70 \%$ were observed in DOPAC, HVA and in the DOPAC/DA and HVA/DA ratios between 20 and 32 months of age in this area (Fig. 2).

As in the ventral tegmental area, no significant changes were observed in DA levels in the frontal cortex with aging (Fig. 2). In contrast to the ventral tegmental area the metabolites DOPAC and HVA were already significantly reduced in this area at 20 months of age. For DOPAC this reduction was followed by an elevation between 20 and 32 months of age (Fig. 2), which was mainly due to the high levels in testosterone-treated aged rats (see below). The HVA/DA ratio in the frontal cortex was reduced at 32 months of age (Fig. 2).

An elevation of DOPAC in the frontal cortex following testosterone treatment was on the verge of statistical significance (ANOVA: $p=0.051$; Fig. 2).

In addition to the nigrostriatal and mesocortical system, DA levels were also studied in the locus coeruleus and hippocampus. No statistically significant effects of either age or treatment were observed on DA levels in either area (Table 2).

Coeruleohippocampal system. Marked age-related changes were observed in the noradrenergic projections to the hippocampus (Fig. 3). NA was reduced in both areas at 32 months of age and the metabolite MHPG showed a significant reduction already at 20 months in both areas. In the hippocampus MHPG was even further reduced at 32 months of age.

The MHPG/NA ratio declined between 5 and 20 months in the locus coeruleus and hippocampus. In the hippocampus this ratio declined even further between 20 and 32 months of age (Fig. 3).

A main effect of testosterone treatment on MHPG levels was observed in the locus coeruleus. Although there was no age $\times$ treatment interaction, this effect was most pronounced in young animals (Fig. 3). No changes in the MHPG/NA ratio following testosterone treatment were observed in this area. In the hippocampus separate comparisons were made for MHPG levels in each age-group because of the significant age $\times$ treatment interaction in this area (ANOVA: $p<0.01$ ). These comparisons revealed significant increases in the level of MHPG in young and middleaged animals, but not in aged animals (Fig. 3). A significant age $x$ treatment interaction also occurred for the MHPG/NA ratio in hippocampus (ANOVA: $p=0.014$ ). Separate comparisons revealed a significant decrease of this ratio in aged animals following testosterone treatment.

In addition to coeruleohippocampal projections, NA levels were also studied in nigrostriatal and mesocortical areas (Table 

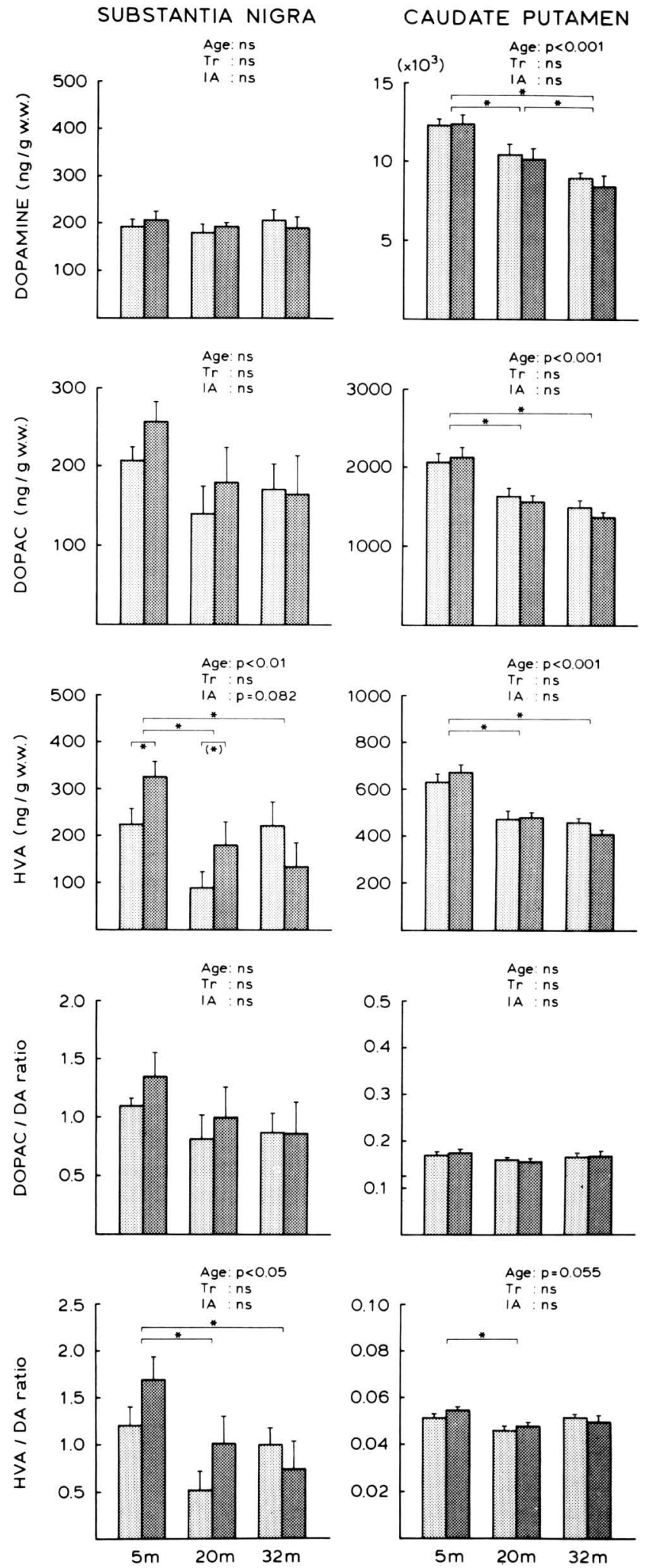

SHAM

TESTOSTERONE
3). Because an age $\times$ treatment interaction approached statistical significance in the striatum (ANOVA: $p=0.095$ ), separate comparisons were made for sham- and testosterone-treated animals in this area. A significant increase in NA levels was observed in sham-treated 20- and 32-month-old rats (ONEWAY: $p<0.01$; SNK: $p<0.05$ ). In testosterone-treated animals a similar increase just failed to reach significance (ONEWAY: $p=0.056$ ).

Serotonergic changes. 5-HT levels were significantly elevated in the substantia nigra of middle-aged animals and showed a decrease between 20 and 32 months of age (Table 4). The 5-HIAA/ 5-HT ratio in this area increased significantly between 20 and 32 months of age in sham-treated animals (ONEWAY: $p=0.036$; SNK: $p<0.05$ ) but not in testosterone-treated animals (ONEWAY: $p=0.481$; Table 4). Separate comparisons were made in this case because the 5-HIAA/5-HT ratio in the substantia nigra was affected by both age and treatment (ANOVA: $p<0.05$ ). Testosterone treatment resulted in a reduction of the 5-HIAA/5-HT ratio in the substantia nigra in young animals only (ONEWAY: $p<0.05$ ). Neither age nor testosterone affected serotonin metabolism in the striatum.

5-HIAA was reduced in the ventral tegmental area at 20 months of age. This reduction was followed by an elevation between 20 and 32 months resulting in levels that were not different from those of young animals (Table 4). The 5-HIAA/5-HT ratio showed corresponding changes in this area, being reduced in middle-aged animals as compared with young and aged ones.

In the frontal cortex a pattern contrary to that of the ventral tegmental area was observed, viz. an increase in 5-HIAA between 5 and 20 months of age followed by a decrease between 20 and 32 months (Table 4). The 5-HIAA/5-HT ratio in the frontal cortex was elevated at 20 and 32 months of age. Testosterone did not affect serotonin metabolism in the ventral tegmental area nor in the frontal cortex.

Neither age nor testosterone affected 5-HT or 5-HIAA levels in the locus coeruleus. However, the 5-HIAA/5-HT ratio in this area tended to increase following testosterone treatment (ANOVA: $p=0.059$; Table 4).

In the hippocampus an age $\times$ treatment interaction for 5-HT was observed (ANOVA: $p<0.01$ ). Separate comparisons revealed that 5-HT was reduced at 20 months of age and even further at 32 months in sham-treated animals, but not in testosterone-treated animals (Table 4). 5-HT content was reduced in young testosterone-treated animals in this area. 5-HIAA levels also declined with age in the hippocampus. The 5-HIAA/5-HT ratio showed a significant age $\times$ treatment interaction (ANOVA: $p<0.01$ ). Multiple comparisons revealed an increase of this ratio following testosterone treatment in young animals only (ONEWAY: $p<0.01$; Table 4).

\section{DISCUSSION}

The present study provides for the first time detailed information on age-related changes in monoamine metabolism in the Brown-Norway rat, a strain which is particularly useful for aging studies because of the multiple pathological changes in senescence (55) and the rectangular survival curve (37). In addition, the simultaneous study of monoamine metabolism in areas con-

FIG. 1. Changes in DA, DOPAC and HVA levels and in DOPAC/DA and HVA/DA ratios in the nigrostriatal system with aging and following testosterone treatment. Bars represent means \pm S.E.M. Main effects of ANOVA [age, treatment (Tr) and age $\times$ treatment interaction (IA)] are indicated in the upper right-hand corner of each histogram. *Difference between groups as indicated (SNK: $p<0.05$ for comparisons between age groups; ONEWAY: $p<0.05$ for comparisons between sham- and testosterone-treated animals). ns, not significant. Abbreviations: DA, dopamine; DOPAC, 3,4-dihydroxyphenylacetic acid; HVA, homovanillic acid. 

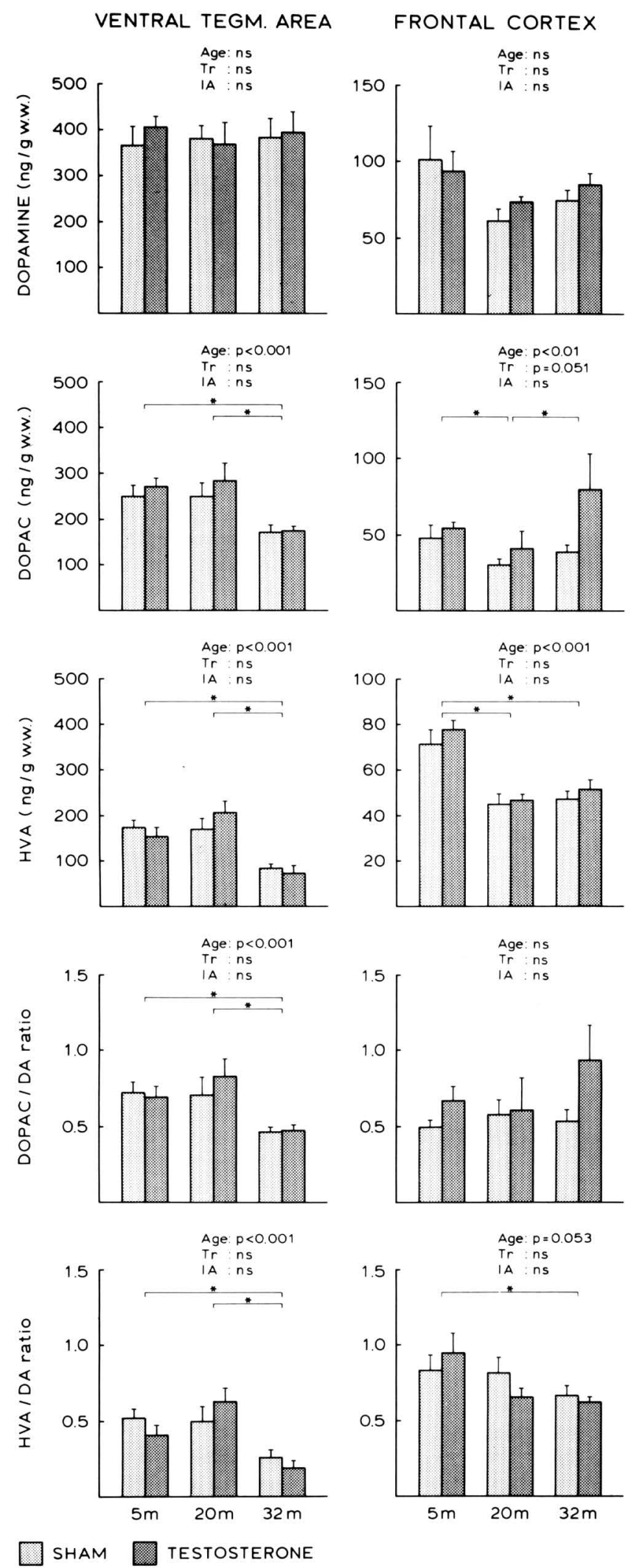

FIG. 2. Changes in DA, DOPAC and HVA levels and in DOPAC/DA and HVA/DA ratios in the mesocortical system with aging and following testosterone treatment. Main effects of ANOVA and multiple comparisons are indicated as in Fig. 1. Abbreviations as in Fig. 1.
TABLE 2

CONCENTRATIONS OF DA (ng/g WET WEIGHT) IN LOCUS COERULEUS AND HIPPOCAMPUS IN SHAM- AND TESTOSTERONE-TREATED RATS

\begin{tabular}{lcccc}
\hline & \multicolumn{2}{c}{ Locus Coeruleus } & \multicolumn{2}{c}{ Hippocampus } \\
$\begin{array}{l}\text { Age } \\
\text { (months) }\end{array}$ & Sham & Testosterone & Sham & Testosterone \\
\hline & & & & \\
5 & $71.4 \pm 5.6$ & $94.6 \pm 13.1$ & $8.7 \pm 1.8$ & $9.6 \pm 0.3$ \\
20 & $81.8 \pm 7.9$ & $92.1 \pm 11.1$ & $9.3 \pm 1.8$ & $9.3 \pm 1.8$ \\
32 & $71.6 \pm 4.9$ & $65.2 \pm 6.2$ & $7.0 \pm 0.6$ & $9.8 \pm 1.2$
\end{tabular}

Values are means \pm S.E.M.; the number of animals in each age/treatment group varied between 6 and 8 (see text). No statistically significant effects of age and treatment or age $\times$ treatment interaction were observed (ANOVA: $p>0.10$ ).

taining catecholaminergic cell bodies (substantia nigra, ventral tegmental area and locus coeruleus), and in their projection areas (striatum, frontal cortex and hippocampus) permits an interpretation in terms of changes in discrete projection systems.

The present results indicate a variety of changes in monoaminergic systems with aging in the Brown-Norway rat. The gradual decrease in DA, DOPAC and HVA in the striatum confirms earlier reports on senescent (i.e., at $50 \%$ survival) SpragueDawley and Wistar rats $(7,36,42,48)$, although others have failed to find similar changes in these strains $(15,30)$. In view of the unchanged DOPAC/DA and HVA/DA ratios, the decline in DA, DOPAC and HVA might indicate a gradual loss of dopaminergic input in the striatum with aging without compensatory activation of the remaining terminals. The observed 30\% DA depletion in senescent animals is probably too moderate to cause such an activation [cf. (2)]. On the other hand, striatal DA uptake was reported to be unaffected in senescent rats, suggesting that the DA terminals in striatum remained intact [e.g., (33) and (49)]. A reduction in striatal DA synthesis, which would be consistent with reports on reduced tyrosine hydroxylase activity in this area with aging $(42,44,50)$, might be an alternative explanation for the observed changes. Contrary to the report of Ponzio et al. (42), DA levels were not found to be decreased in the substantia nigra in senescence. Therefore, our results also fail to support the reduced catecholamine fluorescence in the substantia nigra of senescent mice reported by McNeill et al. (29) and the dramatic cell loss in this area in senescent F344 rats reported by Sabel and Stein (46). The reductions in HVA/DA ratio rather suggest a decrease in dendritic release of DA within the substantia nigra with aging. Such a decrease might imply a reduced integration of neuronal activity in the substantia nigra (11). The absence of significant changes in DOPAC is in line with the predominance of the 3-methoxytyramine pathway in the substantia nigra (38). In summary, nigrostriatal changes in the aging Brown-Norway rat appear to consist of a decrease in the activity of DA neurons in the substantia nigra and a failure to maintain the integrity and/or function of distant projections.

Age-related changes in the mesocortical system followed a different pattern. The cause of the decrease in DA metabolism in the ventral tegmental area which was much more dramatic than in the substantia nigra and which occurred at an older age remains to be elucidated. The reduced levels of DOPAC and HVA in frontal cortex at 20 months of age, in combination with unchanged DOPAC/DA and HVA/DA ratios, suggest a loss of dopaminergic input, or, alternatively, a decrease in DA synthesis in this area already in middle-aged animals. The reduction in HVA/DA at 32 months might indicate a reduction in the activity of dopaminer- 
TABLE 3

CONCENTRATIONS OF NA (ng/g WET WEIGHT) IN NIGROSTRIATAL AND MESOCORTICAL AREAS OF SHAM- AND TESTOSTERONE-TREATED RATS

\begin{tabular}{|c|c|c|c|c|c|c|c|c|}
\hline \multirow{2}{*}{$\begin{array}{l}\text { Age } \\
\text { (months) }\end{array}$} & \multicolumn{2}{|c|}{ Substantia Nigra } & \multicolumn{2}{|c|}{ Striatum } & \multicolumn{2}{|c|}{ Ventral Tegmental Area } & \multicolumn{2}{|c|}{ Frontal Cortex } \\
\hline & Sham & Testosterone & Sham & Testosterone & Sham & Testosterone & Sham & Testosterone \\
\hline 5 & $217 \pm 11$ & $219 \pm 12$ & $91 \pm 4$ & $119 \pm 16$ & $762 \pm 33$ & $806 \pm 37$ & $433 \pm 16$ & $416 \pm 12$ \\
\hline 20 & $191 \pm 27$ & $248 \pm 25$ & $194 \pm 51^{*}$ & $137 \pm 23$ & $730 \pm 77$ & $730 \pm 99$ & $421 \pm 24$ & $426 \pm 17$ \\
\hline 32 & $235 \pm 23$ & $211 \pm 21$ & $144 \pm 11 *$ & $188 \pm 19$ & $661 \pm 32$ & $705 \pm 32$ & $425 \pm 19$ & $399 \pm 20$ \\
\hline
\end{tabular}

Values are means \pm S.E.M.; the number of animals in each age/treatment group varied between 6 and 8 (see text).

*Different from 5-month-old rats (SNK: $p<0.05$ ).

gic terminals in the frontal cortex in senescence. In summary, the mesocortical changes observed in the present study suggest a decrease in DA synthesis and/or a depletion of dopaminergic terminals in the frontal cortex at middle-age and a marked reduction in the activity of this system in senescence.

The noradrenergic changes in the locus coeruleus and hippocampus, which receives a major noradrenergic input from the locus coeruleus (25), indicate progressive degenerative changes in this system with aging. The reduced MHPG/NA ratio in both areas at 20 months of age suggests a reduction in the activity of coeruleohippocampal projections which is already apparent at middle-age. A reduction in activity of noradrenergic cells is consistent with the reduced firing rate of noradrenergic neurons in the locus coeruleus of 10- and 22-month-old rats (40). The reduced NA levels in locus coeruleus and hippocampus at 32 months of age support evidence of reduced NA synthesis in both regions in senescence [e.g., (41)]. Alternatively, a loss of noradrenergic cell bodies in the locus coeruleus as reported in senescent mice (51), in association with a loss of noradrenergic terminals in the hippocampus, might explain our findings. However, Goldman and

TABLE 4

CONCENTRATIONS OF 5-HT AND 5-HIAA (ng/g WET WEIGHT) AND 5-HIAA/5-HT RATIO IN BRAIN REGIONS OF SHAM- AND TESTOSTERONE-TREATED RATS

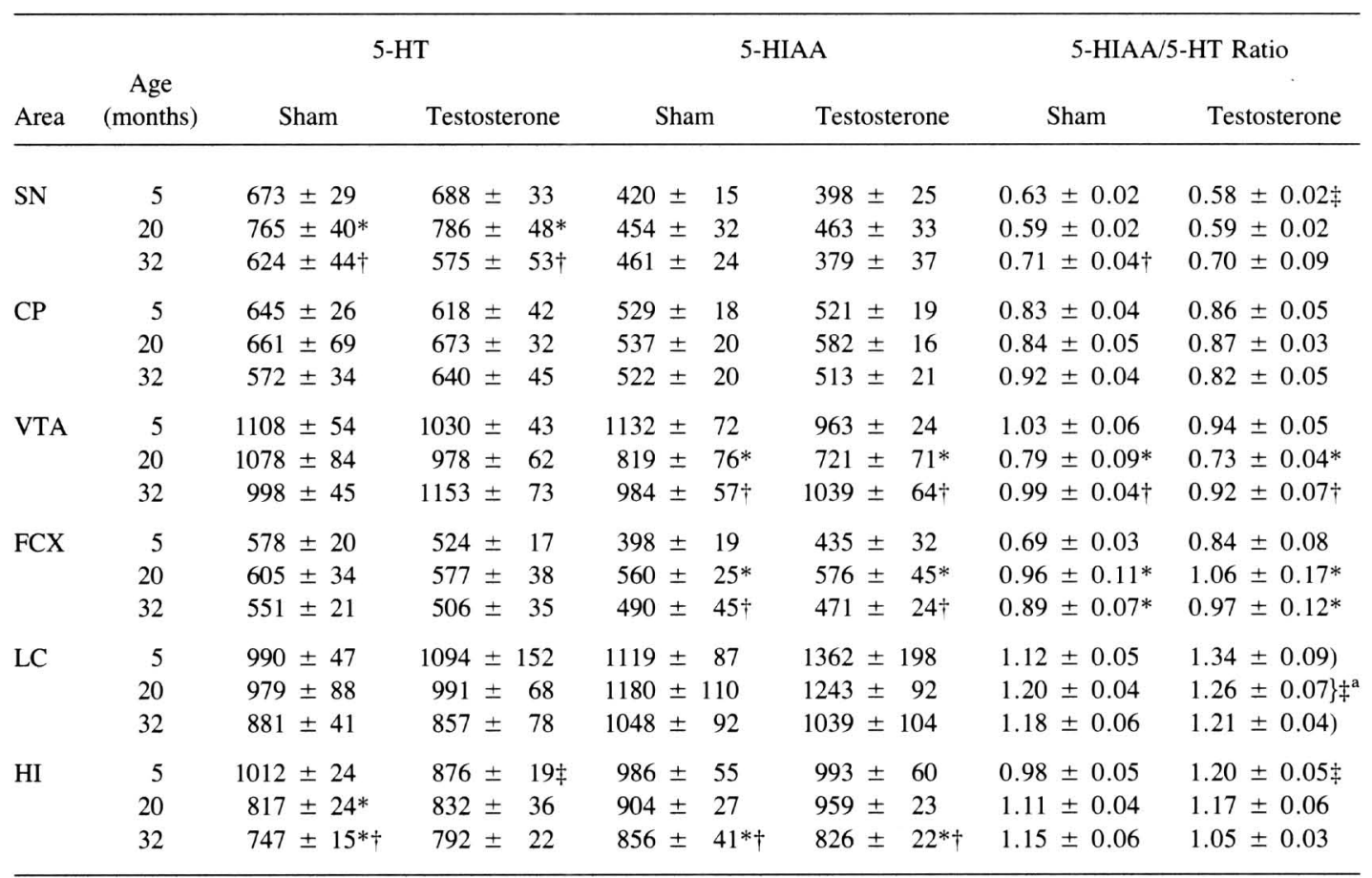

Values are means \pm S.E.M.; the number of animals in each age/treatment group varied between 6 and 8 (see text). If no treatment effect or age $\times$ treatment interaction was observed (ANOVA: $p>0.10$ ) sham- and testosterone-treated animals were pooled and differences between age-groups were indicated by using the same symbol for sham- and testosterone-treated animals. In all other cases differences between age-groups are indicated separately for sham- and testosterone-treated animals.

$*$ Different from 5-month-old rats (SNK: $p<0.05$ ).

+ Different from 20-month-old rats (SNK: $p<0.05$ ).

$\ddagger$ Different from sham-treated animals (ONEWAY: $p<0.05 ;{ }^{a} p=0.059$ ).

Abbreviations: CP, caudate putamen; FCX, frontal cortex; HI, hippocampus; LC, locus coeruleus; SN, substantia nigra; VTA, ventral tegmental area. 
LOCUS COERULEUS HIPPOCAMPUS
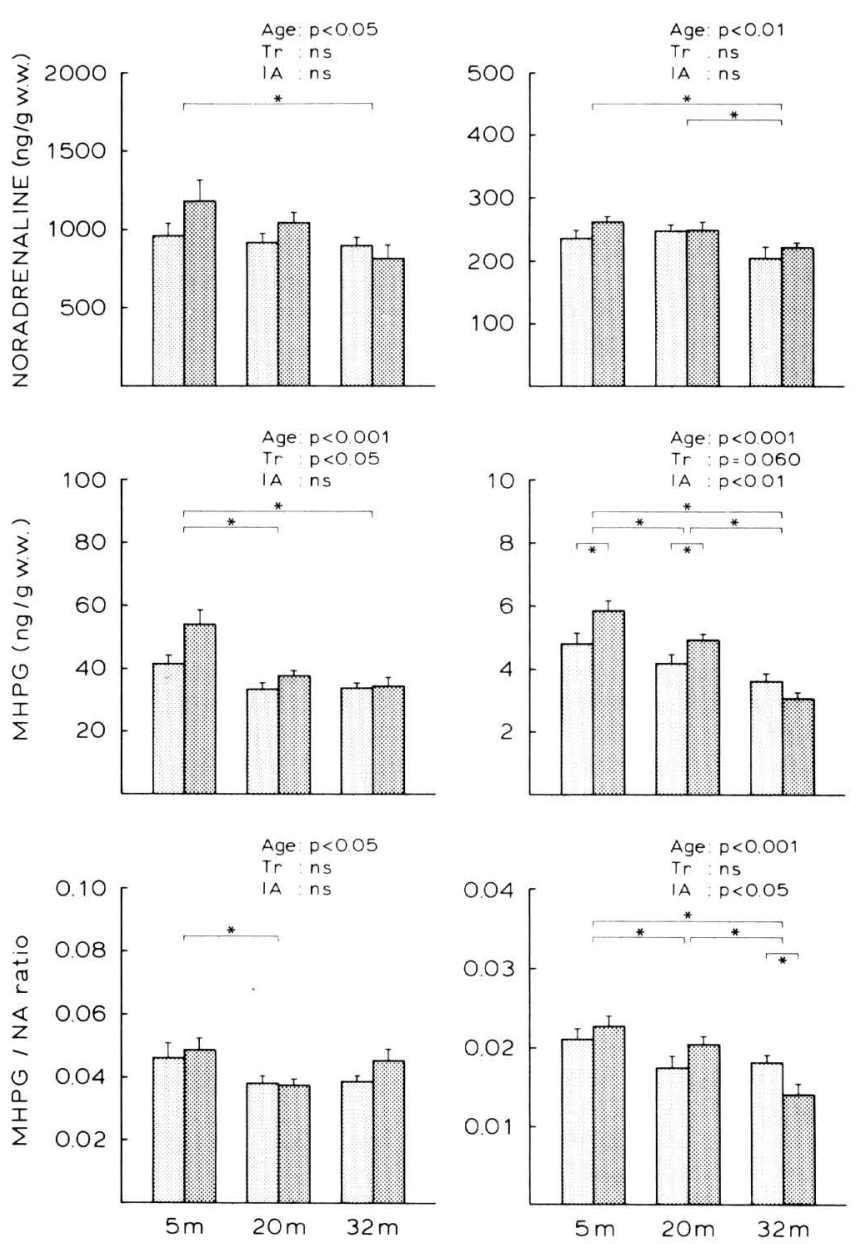

SHAM

TESTOSTERONE

FIG. 3. Changes in NA and MHPG levels and in MHPG/NA ratio in the coeruleohippocampal system with aging and following testosterone treatment. Main effects of ANOVA and multiple comparisons are indicated as in Fig. 1. Abbreviations: NA, noradrenaline; MHPG, 3-methoxy-4-hydrophenylethyleneglycol.

Coleman (16) found no cell loss in the locus coeruleus of F344 rats up to 32 months of age. It is of interest that Roubein et al. (45) reported reduced NA levels in the brainstem of SpragueDawley rats from 12 months onwards, whereas McIntosh and Westfall (28) found no change in NA levels in this region in F344 rats until 24 months of age. Hence, the rate of age-related changes in the locus coeruleus of the F344 might differ from that in Sprague-Dawley and Brown-Norway rats.

The age-related increase in NA concentration in the striatum is hard to interpret as it might reflect changes in NA synthesis, metabolism, release, uptake, etc. In the absence of corresponding data on the metabolite MHPG little can be said on mechanisms underlying this increase. Of course, NA levels in the striatum are low as compared to other regions. In addition, striatal DA levels are much higher than NA levels. Therefore, the significance of the striatal NA innervation is also difficult to assess.

The serotonergic changes observed in the present study agree with data reported by Meek et al. (34). However, others have found unchanged 5-HT levels in the hippocampus in senescent rats $(15,42,47)$. No changes in 5-HT concentration were found in striatum and frontal cortex. Therefore, the remarkable increase in 5-HIAA/5-HT ratio in frontal cortex in middle-aged animals does not appear to be a compensation for a reduction in the number of serotonergic terminals in this region. In contrast, the 5HIAA/5-HT ratio was reduced in the ventral tegmental area of middle-aged animals. Since the ventral tegmental area encloses the majority of serotonergic projections to the frontal cortex (24), these findings might indicate that an increase in the activity of serotonergic terminals corresponds to a decrease of axonal 5HIAA content.

None of the changes in monoamine metabolism which were observed in the senescent Brown-Norway rat in the present study were restored by testosterone administration. Testosterone administration to senescent rats was previously shown to restore vasopressin innervation in areas including the substantia nigra, the ventral tegmental area and the locus coeruleus (17). The animals used in the present study also showed a significant increase in central vasopressin levels following testosterone treatment, as published in a separate paper (18). Therefore, the lack of effects of such treatment on central monoamine metabolism in aged rats casts doubt on a mediatory role of vasopressin in this respect. Testosterone administration also failed to restore central choline acetyltransferase activity in these animals (18). However, marked effects of testosterone were found in young animals. The elevation of HVA in the substantia nigra of young testosterone-treated animals suggests an increase in dopamine metabolism in this area. Alderson and Baum reported a stimulatory effect of sex steroids on ventral tegmental area projections (1), but the present work fails to support this finding. MHPG was increased in the locus coeruleus and hippocampus following testosterone treatment, suggesting an increase in synthesis and turnover of NA in the coeruleohippocampal system. Decreased 5-HT levels were observed in the hippocampus of young animals following testosterone administration. A suppression of 5-HT levels by testosterone is in line with the sexual dimorphism in central 5-HT as reported by Carlsson and Carlsson (9). In addition, these authors have also found a marked elevation of 5-HT in male rat brain following castration.

Sex steroids might directly stimulate monoaminergic neurons via specific receptors. Binding of sex steroids to catecholamine neurons was demonstrated in the locus coeruleus and other brain stem areas (21), but, as far as we know, not in the substantia nigra or the ventral tegmental area. This might explain the relative predominance of testosterone effects in coeruleohippocampal projections in the present study. Alternatively, testosterone administration might alter the activity of enzymes involved in monoamine metabolism. The elevated levels of MHPG in locus coeruleus and hippocampus in testosterone-treated animals appear to be consistent with increases in monoamine oxidase activity as reported in brain regions of castrated male rats following testosterone administration (26).

The fact that the effects of testosterone treatment were most pronounced in young animals suggests that young animals might be more sensitive in this respect than aged ones. Decreased sensitivity to testosterone might be related to decreased numbers and affinities of androgen receptors and aromatase activity in specific regions of the senescent rat brain (10).

In conclusion, the present study indicates a variety of changes in monoamine metabolism with aging in the Brown-Norway rat. Differences were not only observed between different projection systems, but also between areas containing cell bodies and associated areas containing nerve terminals (e.g., substantia nigra and striatum). In the ventral tegmental area a reduction in dopamine metabolism was observed which was much more dramatic than in the substantia nigra and which occurred at a higher age. In addi- 
tion, evidence suggesting a gradual decrease in the integrity of dopaminergic innervation without a compensatory rise in metabolic activity was found in the striatum. Progressive degenerative changes were seen in coeruleohippocampal projections, which might correspond to cell loss in the locus coeruleus in senescence. Although testosterone supplementation resulted in a significant increase in monoamine metabolism in several brain structures, these effects were most pronounced in young animals, suggesting alterations in steroid receptor or postreceptor mechanisms with aging. The present results do not support a role of central vasopressin innervation in age-related changes in monoamine metabolism.

\section{ACKNOWLEDGEMENTS}

The authors thank Mr. H. van Galen and Ms. Tj. van der Woude for expert technical assistance and Mr. B. Schillings for secretarial help. Testosterone levels were determined at the laboratory for endocrinology (head: Dr. E. Endert) at the AMC in Amsterdam. We also thank Mr. H. Stoffels for preparing the illustrations and Mr. A. Janssen for correcting the English. The present research was supported by the Foundation for Medical and Health Research (MEDIGON, Grant 900-552-056). Aged rats were made available with support from the Netherlands Organization for Scientific Research. Middle-aged and young animals were made available by the European Communities Concerted Action on Cellular Aging and Disease (EURAGE)

\section{REFERENCES}

1. Alderson, L. M.; Baum, M. J. Differential effects of gonadal steroids on dopamine metabolism in mesolimbic and nigro-striatal pathways of male rat brain. Brain Res. 218:189-206; 1981.

2. Altar, C. A.; Marien, M. R.; Marshall, J. F. Time course of adaptations in dopamine biosynthesis, metabolism, and release following nigrostriatal lesions: implications for behavioral recovery from brain injury. J. Neurochem. 48:390-399; 1987.

3. Besnard, F.; Kempf, E.; Fuhrmann, G.; Kempf, J.; Ebel, A. Influence of mouse genotype on responses of central biogenic amines to alcohol intoxication and aging. Alcohol 3:345-350; 1986.

4. Björklund, A.; Lindvall, O. Dopamine-containing systems in the CNS. In: Björklund, A.; Hökfelt, T., eds. Handbook of chemical neuroanatomy. vol. 2. Classical transmitters in the CNS, part I. Amsterdam: Elsevier; 1984:55-122.

5. Bondareff, W.; Mountjoy, C. Q.; Roth, M. Loss of neurons of origin of the adrenergic projection to cerebral cortex (nucleus locus ceruleus) in senile dementia. Neurology 32:164-168; 1982.

6. Burek, J. D. Pathology of aging rats. A morphological and experimental study of age-associated lesions in aging $\mathrm{BN} / \mathrm{Bi}, \mathrm{WAG} / \mathrm{Rij}$ and $(\mathrm{WAG} \times \mathrm{BN}) \mathrm{F} 1$ rats. Boca Raton: CRC Press; 1978.

7. Carfagna, N.; Trunzo, F.; Moretti, A. Brain catecholamine content and turnover in aging rats. Exp. Gerontol. 20:265-269; 1985.

8. Carlsson, A.; Adolfsson, R.; Aquilonius, S.-M.; Gottfries, C.-G.; Oreland, L.; Svennerholm, L.; Winblad, B. Biogenic amines in human brain in normal aging, senile dementia, and chronic alcoholism. In: Goldstein, M., ed. Ergot compounds and brain function-neuroendocrine and neuropsychiatric aspects. New York: Raven Press; 1980:295-304

9. Carlsson, M.; Carlsson, A. A regional study of sex differences in rat brain serotonin. Prog. Neuropsychopharmacol. Biol. Psychiatry 12: $53-61 ; 1988$

10. Chambers, K. C.; Thornton, J. E.; Roselli, C. E. Age-related deficits in male sexual behavior are accompanied by changes in androgen metabolism and binding in brain. Soc. Neurosci. Abstr. 14:98; 1988

11. Cheramy, A.; Leviel, V.; Glowinski, J. Dendritic release of dopamine in the substantia nigra. Nature 289:537-542; 1981.

12. Conover, W. J. Practical non-parametric statistics. New York: J. Wiley \& Sons; 1980.

13. Fallon, J. H.; Loughlin, S. E. Monoamine innervation of cerebral cortex and a theory of the role of monoamines in cerebral cortex and basal ganglia. In: Jones, E. G.; Peters, A., eds. Cerebral cortex. vol. 6. Further aspects of cortical function, including hippocampus. New York: Plenum Press; 1987:41-127.

14. Fliers, E.; De Vries, G. J.; Swaab, D. F. Changes with aging in the vasopressin and oxytocin innervation of the rat brain. Brain Res. 348:1-8; 1985 .

15. Godefroy, F.; Bassant, M. H.; Weil-Fugazza, J.; Lamour, Y. Agerelated changes in dopaminergic and serotonergic indices in the rat forebrain. Neurobiol. Aging 10:187-190; 1989

16. Goldman, G.; Coleman, P. D. Neuron numbers in locus coeruleus do not change with age in Fisher 344 rat. Neurobiol. Aging 2:33-36; 1981.

17. Goudsmit, E.; Fliers, E.; Swaab, D. F. Testosterone supplementation restores vasopressin innervation in the senescent rat brain. Brain Res. 473:306-313; 1988
18. Goudsmit, E.; Luine, V. N.; Swaab, D. F. Testosterone locally increases vasopressin content but fails to restore choline acetyltransferase activity in other regions in the senescent male rat brain. Neurosci. Lett. 112:290-296; 1990.

19. Goudsmit, E.; Van De Poll, N. E.; Swaab, D. F. Testosterone fails to reverse spatial memory decline in aged rats and impairs retention in young and middle-aged animals. Behav. Neural Biol. 53:6-20; 1990

20. Heffner, T. G.; Hartman, J. A.; Seiden, L. S. A rapid method for the regional dissection of the rat brain. Pharmacol. Biochem. Behav. 13: $453-456 ; 1980$.

21. Heritage, A. S.; Stumpf, W. E.; Sar, M.; Grant, L. D. Brainstem catecholamine neurons are target sites for sex steroid hormones. Science 207:1377-1379; 1980

22. Ichimiya, Y.; Arai, H.; Kosaka, K.; Iizuka, R. Morphological and biochemical changes in the cholinergic and monoaminergic systems in Alzheimer-type dementia. Acta Neuropathol. (Berl.) 70:112-116; 1986

23. Joynt, R. J.; McNeill, T. H. Neuropeptides in aging and dementia. Peptides 5:269-274; 1984.

24. Kalsbeek, A.; Feenstra, M. G. P.; Van Galen, H.; Uylings, H. B. M. Monoamine and metabolite levels in the prefrontal cortex and the mesolimbic forebrain following neonatal lesions of the ventral tegmental area. Brain Res. 479:339-343; 1989.

25. Loy, R.; Koziell, D. A.; Lindsey, J. D.; Moore, R. Y. Noradrenergic innervation of the adult rat hippocampal formation. J. Comp. Neurol. 189:699-710; 1980.

26. Luine, V. N.; Khylchevskaya, R. I.; McEwen, B. S. Effect of gonadal steroids on activities of monoamine oxidase and choline acetylase in rat brain. Brain Res. 86:293-306; 1975.

27. McGeer, P. L.; McGeer, E. G.; Suzuki, J. S. Aging and extrapyramidal function. Arch. Neurol. 34:33-35; 1977.

28. McIntosh, H. H.; Westfall, T. C. Influence of aging on catecholamine levels, accumulation, and release in F-344 rats. Neurobiol. Aging 8:233-239; 1987.

29. McNeill, T. H.; Koek, L. L.; Haycock, J. W. The nigrostriatal system and aging. Peptides 5(Suppl. 1):263-268; 1984.

30. Machado, A.; Cano, J.; Santiago, M. The change with age in biogenic amines and their metabolites in the striatum of the rat. Arch. Gerontol. Geriatr. 5:333-342; 1986.

31. Mann, D. M. A.; Yates, P. O.; Marcyniuk, B. Monoaminergic neurotransmitter systems in presenile Alzheimer's disease and in senile dementia of Alzheimer type. Clin. Neuropathol. 3:199-205; 1984.

32. Mann, D. M. A.; Yates, P. O.; Marcyniuk, B. Alzheimer's presenile dementia, senile dementia of Alzheimer type and Down's syndrome in middle age form an age related continuum of pathological changes. Neuropathol. Appl. Neurobiol. 10:185-207; 1984.

33. Marshall, J. F.; Altar, C. A. Striatal dopamine uptake and swim performance of the aged rat. Brain Res. 379:112-117; 1986.

34. Meek, J. L.; Bertilsson, L.; Cheney, D. L.; Zsilla, G.; Costa, E. Aging-induced changes in acetylcholine and serotonin content of discrete brain nuclei. J. Gerontol. 32:129-131; 1977.

35. Moore, R. Y.; Card, J. P. Noradrenaline-containing neuron systems. In: Björklund, A.; Hökfelt, T., eds. Handbook of chemical neuroanatomy. vol. 2. Classical transmitters in the CNS, part I. Amsterdam: Elsevier; 1984:123-156 
36. Moretti, A.; Carfagna, N.; Trunzo, F. Effect of aging on monoamines and their metabolites in the rat brain. Neurochem. Res. 12: 1035-1039; 1987.

37. Mos, J.; Hollander, C. F. Analysis of survival data on aging rat cohorts: pitfalls and some practical considerations. Mech. Ageing Dev. 38:89-105; 1987

38. Nissbrandt, H.; Carlsson, A. Turnover of dopamine and dopamine metabolites in rat brain: comparison between striatum and substantia nigra. J. Neurochem. 49:959-967; 1987.

39. Olpe, H.-R.; Baltzer, V. Vasopressin activates noradrenergic neurons in the rat locus coeruleus: a microiontophoretic investigation. Eur. J. Pharmacol. 73:377-378; 1981.

40. Olpe, H.-R.; Steinmann, M. W. Age-related decline in the activity of noradrenergic neurons of the rat locus coeruleus. Brain Res. 251: 174-176; 1982.

41. Ponzio, F.; Brunello, N.; Algeri, S. Catecholamine synthesis in brain of ageing rat. J. Neurochem. 30:1617-1620; 1978.

42. Ponzio, F.; Calderine, G.; Lomuscio, G.; Vantini, G.; Toffano, G.; Algeri, S. Changes in monoamines and their metabolite levels in some brain regions of aged rats. Neurobiol. Aging 3:23-29; 1982.

43. Pratt, J. J.; Wiegman, T.; Lappöhn, R. E.; Woldering, M. G. Estimation of plasma testosterone without extraction and chromatography. Clin. Chim. Acta 59:337-346; 1975.

44. Reis, D. J.; Ross, R. A.; Tong, H. J. Changes in the activity and amounts of enzymes synthesizing catecholamines and acetylcholine in brain, adrenal medulla, and sympathetic ganglia of aged rat and mouse. Brain Res. 136:465-474; 1977.

45. Roubein, I. F.; Embree, L. J.; Jackson, D. W. Changes in catecholamine levels in discrete regions of rat brain during aging. Exp. Aging Res. 12:193-196; 1986.
46. Sabel, B. A.; Stein, D. G. Extensive loss of subcortical neurons in the aging rat brain. Exp. Neurol. 73:507-516; 1981.

47. Santiago, M.; Machado, A.; Reinoso-Suarez, F.; Cano, J. Changes in biogenic amines in rat hippocampus during development and aging. Life Sci. 42:2503-2508; 1988

48. Strong, R.; Samorajski, T.; Gottesfeld, Z. Regional mapping of neostriatal neurotransmitter systems as a function of aging. J. Neurochem. 39:831-836; 1982.

49. Strong, R.; Samorajski, T.; Gottesfeld, Z. High-affinity uptake of neurotransmitters in rat neostriatum: effects of aging. J. Neurochem 43:1766-1768; 1984.

50. Strong, R.; Waymire, J. C.; Samorajski, T.; Gottesfeld, Z. Regional analysis of neostriatal cholinergic and dopaminergic receptor binding and tyrosine hydroxylase activity as a function of aging. Neurochem. Res. 9:1641-1652; 1984.

51. Sturrock, R. R.; Rao, K. A. A quantitative histological study of neuronal loss from the locus coeruleus of aging mice. Neuropathol. Appl. Neurobiol. 11:55-60; 1985.

52. Vijayashankar, N.; Brody, H. A quantitative study of the pigmented neurons in the nuclei locus coeruleus and subcoeruleus in man as related to aging. J. Neuropathol. Exp. Neurol. 38:490-497; 1979.

53. Watanabe, H. Substrain differences of age-related changes in in vivo dopamine synthesis in the striatum and nucleus accumbens of the rat brain. J. Pharmacobiodyn. 10:317-320; 1987.

54. Westerink, B. H. C. Analysis of trace amounts of catecholamines and related compounds in brain tissue: a study near the detection limit of liquid chromatography with electrochemical detection. J Liquid Chromatog. 6:2337-2351; 1983

55. Zurcher, C.; Hollander, C. F. Multiple pathological changes in aging rat and man. Exp. Biol. Med. 7:55-62; 1982. 